\title{
Cohesion and Cooperation in Autistic Children's Discourse
}

\author{
Author: \\ Dalia M. Hamed \\ Lecturer of English Linguistics \\ Faculty of Education - Tanta University, Egypt \\ daliahamed53@yahoo.com
}

\section{Declarations:}

*Availability of data and material:

All data generated or analyzed during this study are included in this article.

*The author declares no conflict of interest.

*The author declares that she is the sole author, no other author contributed to this

paper in any form.

*This paper has not received any funding.

This research did not receive any specific grant from funding agencies in the public, commercial, or not-for-profit sectors.

\section{Abstract}

Autism Spectrum Disorder causes difficulties in interaction and communication, hence this study is an attempt to shed some light on autistic children's discourse concerning the way they employ cohesive ties and show cooperation during conversation. This is a preliminary step to propose some suggestions that may help these children with their troubles and challenging conditions. Research method is based on an analysis of the autistic discourse regarding two points: children's observance of the Cooperative Principle in conversation and their use of cohesive ties. Grice's notion of The Cooperative Principle (1975) that governs conversational behaviors assume that conversation is a cooperative endeavor between interactants. Halliday and Has an (1976) discuss the notion of cohesion in discourse and consider that any text should be unified by certain cohesive devices. This study approaches autistic children's discourse from the two perspectives: cooperation and cohesion. It concludes that autistic children employ echolalia to implicate their acceptance of the activity presented, which is a cooperative act. It is concluded that using words relating to the same relevant topic is nearly the only cohesive device employed by autistic children. Research limitation has to do with conducting an analysis of a child's discourse despite the child's inability to communicate and his repetitive linguistic behaviors. The study may be practical in suggesting some directions to improve autistic children's performance and social communication. Echolalia, for instance, may be considered as a positive act of cooperation, and be taken as a step to move forward and train the child to repeat 
and utter a comment or express his desire. Autistic children should be trained to use various cohesive devices, such as synonymy and antonymy. This paper tries to make better language activities related to autistic children.

Key Words: Autism Spectrum Disorder; Discourse; The Cooperative Principle; Cohesive Devices.

Highlights

*Autism Spectrum Disorder and its effects on language skills.

*The Cooperative Maxims and autistic children's discourse

*Cohesive Devices in autistic children's discourse.

*Echolalia in the discourse of children with autism. 


\section{Cohesion and Cooperation in Autistic Children's Discourse 1. Problem Statement}

Being a uniquely human feature, language is mainly a device for the communication of ideas and the negotiation of intentions and beliefs. Communicative messages, accordingly, are at the core of everyday activities. Humans are social creatures who depend on language to interact with each other. This distinguishing feature of linguistic interaction is an unparalleled advantage. The dumb and the deaf have their own special sign language and, consequently, have found a way out of their particular condition so that they may be able to communicate their needs, desires and aspirations. But, what about those who suffer from a neurological disorder that prevents them from acting, reacting or learning like ordinary people?

Autism Spectrum Disorder, a developmental and a neurological disorder, has a severe effect on behavior, interaction and communication. Autism symptoms can be diagnosed at early childhood but last during the person's life. Autistic children have difficulties in any form of social communication. This lifelong disorder makes it necessary to offer a certain treatment to autistic children in an attempt to improve the child's ability to act and react. Hence, this study is an attempt to shed some light on autistic children's discourse concerning the way they employ, or do not employ, cohesive ties and observe, or violate, the Cooperative Principle in conversation. This is a preliminary step to propose some suggestions that may help these children with their troubles and challenging conditions as to discourse communication.

This study attempts to approach autistic children's discourse from two perspectives. The first is that of discourse cohesion. For any conversation to proceed smoothly and develop in a well-organized manner, cohesive ties of discourse have to be employed. Halliday and Hasan (1976) have considered that for any piece of discourse to be communicated effectively, cohesive devices have to be used in order to guarantee discourse organization. They have identified references, substitution, ellipsis, conjunctions and lexical cohesion as being major cohesive devices. Lexical cohesion is about the meaning in text and refers to the use of repetition, synonymy, antonymy, hyponymy, metonymy and word association through collocation.

The second perspective is that of Grice's pragmatic theory of implicature (1975). Pragmatics deals with contextual meaning or meaning in interaction. Isolated words are used to convey a meaning that is completely different from that in an utterance. Pragmatics deals with aspects of meaning in situational contexts. Grice (1975) has theorized the Cooperative Principle which governs conversation. For a conversation to develop, interactants must cooperate in some way. Maxims of 
cooperation, as postulated by Grice (1975), include quantity, quality, relation and manner. Any deliberate violation of these maxims means that the speaker has a meaning implied behind the words uttered. In the case of autistic children, maximviolation is forced due to their neurodevelopmental disorder. Consequently, their unwillingness to cooperate in conversation is justified on the basis of their inability. Checking the maxims violated/observed and identifying the cooperative verbal actions by autistic children are major focal points in this study.

Detecting autistic children's incompetence with discourse cohesion and pragmatic cooperation is an introductory stage to suggest some cues that may help these children with their challenging condition.

\section{Aim and Significance of the Study}

This paper aims at examining the way autistic children use cohesive ties which are proposed by Halliday and Hasan (1976). It also aims to evaluate autistic children's observance of the Cooperative Principle in conversational interactions (Grice, 1975). These indications make us diagnose accurately some aspects of linguistic deficiencies that autistic children experience.

This is significant in the sense that zooming on autistic children's failure in discourse cohesion and conversational cooperation paves the way for offering some solutions that may lessen these children's language troubles.

\section{Research Questions}

What are the cohesive devices that appear clearly in autistic children's discourse?

What are the individual differences as to the use of cohesive devices by the five autistic children?

What are the cohesive devices that are nearly absent in their discourse?

How far can autistic children cooperate in conversation?

What are the proposed suggestions that may develop autistic children's linguistic behavior?

\subsection{Some Studies on Autistic Children}

\section{Literature Review}

The communicative competence of children suffering from Autism Spectrum Disorder is investigated by Tager-Flusberg and Anderson (1991) as they have examined the discourse of autistic children in connection with contingent categories. Autistic boys are compared with children suffering from Down syndrome. Children's utterances are analyzed regarding their use of various categories of contingent discourse. Results prove that Autistic children are found to be more non-contingent, and to show no developmental change in their contingent discourse. 
Tager-Flusberg et al. (2005) investigate language development in autistic children. They explain that communication disorders are mainly influenced by deficits in information processing capabilities and the way people behave in social interactions. It is concluded that these deficits must be handled in order to remedy autistic communicative disorders.

Hagan (2017) has presented a study concerning the discourses of parents and professionals when a child is diagnosed with autism. That study is meaning-making focused. Groups of professionals in an autism assessment centre were called up with parents of four families to receive an autism assessment for their child. Findings show that there is a difference between expert knowledge and parents' way of knowing. The thesis analyzes how parents conform to discourses of diagnosis and how professionals do. Exchanges between parents and professionals are analyzed. They expose further practices of self-subjection and strategies of resistance.

Helland \& Helland (2017) investigate emotional and behavioural needs in children with specific language impairment and children with autism spectrum disorder. Questionnaires are filtered by parents in order to assess children's emotional needs and their linguistic development. Findings prove that emotional and behavioural needs and pragmatic problems are common in both groups of children. Moreover, autistic children are proven to be more impaired.

Loukusa et al (2018) investigate how children with autism spectrum disorder and normal children comprehend scenarios which require contextual inference with the theory of the mind, contextual inference without the theory of the mind, language use and recognition of feelings. The results illustrate the difference between both groups of children in questions demanding contextual understanding. In addition to that, the demand of mind-reading in utterance interpretation increased the difference between groups.

Maciejewska (2019) approaches autistic adolescent communication from a discourse analysis perspective. The article clarifies the way discourse analysis can help interpret autistic adolescent's behavioural communication. Data are based on interviews with autistic adolescent who are asked to complete two tasks: picture description and narrative production. Interviews are analyzed. The study shows the way in which participants, and their relative communication, are directed by the interviewer's linguistic participation.

It follows that many researches have focused on autism as a topic of study. The present study has a differing focus as it traces the manner in which autistic children manage to follow Grice's cooperative principle in order to express their desire to interact in a cooperative manner. It also approaches autistic children's discourse as 
regards its sticking to cohesive devices. These two points, cooperation and cohesion, are crucial in training autistic children to develop communicative skills.

\subsection{Discourse Cohesion}

Cohesion is the connectedness in discourse when the interpretation of a linguistic element depends on the interpretation of another discourse element. A text, according to Halliday and Hasan (1976), is "any passage, spoken or written, of whatever length, that does form a unified whole" and "is best regarded as a semantic unit" (P. 1). Halliday and Hasan (1976) perceive cohesion as the only factor that distinguishes texts from non-texts. They identify five different types of cohesion: reference, substitution, ellipsis, conjunction, and lexical cohesion.

A text is not just a sequence of sentences strung together, but a sequence of units connected in some contextually appropriate ways. "A text as a whole must exhibit the related, but distinguishable properties of cohesion and coherence" (Lyons, 1983, P.198). Thus, cohesion is concerned with formal connectedness. According to McCarthy (2001, P.97), sentence relations with each other and combinations of units of meaning to create coherence "is the results of interaction between the readers world and the text".

Coherence means the connection of ideas at the idea level, and cohesion means the connection of ideas at the sentence level. Coherence means the overall "understandability" of what you write or say. Cohesion analysis has gained much attention in linguistic studies (Halliday \& Hasan (1976), Hasan (1984), Halliday (1985), Hoey (1991), Martin (1992), and Halliday \& Matthiessen (2004)).

According to Halliday and Hasan (1976), reference, substitution ellipsis and conjunction are the basic categories of grammatical cohesion, which refers to the various grammatical devices that can be used to make relations among sentences more explicit. Lexical cohesion is a matter of word-choice.

The coming part gives an explanation of cohesion types: the lexical and grammatical.

References:

Halliday and Hasan (1976) point out that reference features cannot be semantically interpreted without referring to some other features in the text. Pronouns, articles, demonstratives and comparatives are the most common linguistic element as referring devices

Substitution:

Halliday and Hasan (1976) state that substitution takes place when one feature (in a text) replaces a previous word or expression.

Ellipsis: 
Ellipsis is "substitution" by zero. Harmer defines it: "(...) words are deliberately left out of a sentence when the meaning is still clear". (Harmer, 2004, P. 24).

Conjunctions:

Conjunctions show relations between sentences. Coordinating conjunctions include for, and, but, yet or and so. Subordinating conjunctions include when, while, after, before, if, as and although.

Lexical Cohesion:

Halliday and Hasan (1976) define five types of lexical cohesive ties that commonly occur in text.

a- Repetition (or Reiteration) - Occurs when a word form is repeated again in a later section of the text.

b-Repetition through synonymy - Occurs when words share the same meaning. Antonymy is a cohesive semantic linkage established between lexical items of opposite meanings.

Halliday \& Hasan (1976), Hasan (1984) and Martin (1992) define synonymy in a narrower sense: synonymy is a relation between lexical elements whose sense is the same or nearly the same. Halliday and Matthiessen (2004) rank both antonymic and synonymic relations under the category of synonymy

c-Word association through specialization/generalization - Occurs when a specialized/generalized form of an earlier word is used. Hyponymy is a cohesive relationship established between a general (superordinate) concept and (usually more than one) specific (or subordinate) concepts

d-Metonymy is a cohesive relationship established between a concept and its parts.

e- Word association through collocation - it is the co-occurrence of items. Using words related to the same field is a sign of connectedness.

\subsection{Pragmatic Meaning and the Cooperative Principle}

When a speaker uses language to convey a certain message, he has an intention in his mind, which is, sometimes, hidden behind the literal meaning of the uttered words. Hofmann $(1993,273)$ considers pragmatics to be a link "between the literal meaning of a sentence and what it is used to convey". Cabley $(2001,83)$ considers that pragmatics "has come to be applied to the study of language from the point of view of its users, especially of the choices they make, the constraints they encounter in using language in social interaction, and the effect their use of language has on the other participant in an act of communication". Grice's theory of conversational implicature (1975) is a pragmatic approach to language that focuses on the intended meaning in an interactional situation. 
Downes (1998, P. 440-441) considers that "An implicature arises when the use of a particular form of words conveys something which is not part of what has actually been said". Implicature is used by Grice (1975) to account for what a speaker suggests as distinct from what he has literally uttered. Conversational implicatures depend on the context. Grice (1975) has introduced the Co-operative Principle from which he derives a series of conversational maxims. The basic idea is that "language-activity, most typically, is a kind of rational (and purposive) social interaction governed by the principle of co-operation" (Lyons, 1996, P. 277). The Cooperative Principle reads: "Make your conversational contribution such as is required, at the stage at which it occurs, by the accepted purpose or direction of the talk exchange in which you are engaged" (Grice, 1975, P. 45).

Grice derives from the Co-operative Principle some conversational maxims, which support this principle. These maxims are:

Quantity:

A. Make your contribution as informative as is required (for the current purposes of exchange).

B. Do not make your contribution more informative than is required.

Quality:

1- Do not say what you believe to be false.

2- Do not say that for which you lack adequate evidence.

Relation: Be relevant

Manner

1- Avoid obscurity of expression.

2- Avoid ambiguity.

3- Be brief (avoid unnecessary prolixity).

4- Be orderly.

(Grice, 1975, P. 46)

\section{Methodology}

The Rollins Corpus consists of transcripts of video recordings of 5 boys with autism who experience a preschool program for children on the autistic spectrum at the University of Texas at Dallas. These videos are recorded in March 2012. Each child has an initial diagnosis of autism by a neurologist or a psychologist. All children have some expressive vocabulary skills. All children's ages range between two and three years. Carl is about 2;8, Josh is 2;5, Sid is 2;2, Roger is 2;6, and Marshall is 3;1-year-old. All are native English speakers. For each child four video tapes are transcribed. Marshall has a fifth tape. These transcriptions are available online at ( https://asd.talkbank.org/access/English/Rollins.html). 
These transcriptions are downloaded and analyzed manually according to the framework suggested as they form the data of the study. Uttered words by each child are analyzed as regards cohesive devices and pragmatic cooperation. Downloaded files contain many details concerning nonverbal information, which are not the focus of this study. This study is interested in the autistic child's meaningful verbal behavior concerning its cohesion and level of cooperation.

\subsection{The Target Child: Carl}

\section{Analysis/Discussion}

\subsubsection{Carl: $1^{\text {ST }}$ transcription.}

Carl's first session lasts about 48 minutes. The investigator has tried to make Carl get involved in speech, but in vain. The investigator uselessly repeats the same words over and over so that he may induce Carl to respond. The child never cooperates verbally in spite of the fact that he has some linguistic skills. Some instances in which Carl cooperates verbally are the following:

*INV: hi Chi

*CHI: hi

*INV: balloon

*CHI: yyy

*INV: what are you saying Chi?

*CHI: $\quad$ yyy

*INV: who are you talking to?

*CHI: yyy

*INV: hi Chi.

*CHI: hi

Autism Spectrum Disorder is recognized as being an impairment in communicative interactions. This is evident from the above extract as Carl's language is either repeated nonsensical sounds as "yyy" or an echo copying a word uttered by the investigator as "hi". That is apparent as the boy repeats "yyy" regardless of the questions. Though coherence may be achieved by repetition, Carl's repeated sounds or words do not relate to cohesive devices. These repetitions are symptoms of autistic children's discourse (American Psychiatric Association, 2013).

In this session, the only instances in which Carl responds according to Grice's Cooperative Principle and maxims are the times Carl responds saying "hi" to the investigator's greeting. In these instances, Carl observes the maxim of relation by responding in accordance with the investigator's words.

\subsubsection{Carl: $2^{\text {nd }}$ transcription.}


This session, though it lasts about fifty minutes which means that it is nearly of the same time as session one, shows a remarkable development in Carl's interactional behavior.

It seems that Carl begins to make his words, despite being few, relate to one topic: the toys surrounding him. His repetition of words as "a bucket, a barn, a bus, school, dog, farmer, horse, sheep, chicken, shelf, bicycle, bear, airplane, puzzle, book, and dinosaur" is a feature of discourse cohesion. These words belong to the same field of child's toys and puzzles and show the feature of collocating with each other. Carl shows his understanding of opposites through his use of antonymy in "up and down". He also uses the definite article in "the people, the boy, the horse, the bus, the kids, the sheep" as these nouns are identified. Carl shows understanding of references and this is an evidence that he can handle references:

*INV: where are they?

*CHI: ah people.

Carl also uses possessive adjectives well:

*INV: is this your bucket?

*CHI: my bucket

Carl employs substitution as a cohesive device in:

*INV: guess they're gone.

*CHI: all gone.

Carl uses "all" instead of "they". This behavior shows Carl's developing use of cohesive devices. It is noticed that Carl keeps on repeating the words uttered by the investigator, a sign of autistic children's speech. In spite of being a symptom of language disorder, Carl's very repetitions are considered to be a positive signal because repeated words belong to one field and one topic, that of toys. This signal refers to Carl's preparation to develop cohesive skills.

As for pragmatic cooperation, Carl's discourse contribution takes the form of repeating the investigator's words. He could have kept silent but he desires to cooperate in conversation through responding to the investigator's words. Mostly, his words are not the required answers/comments and are mere repetitions of the investigator's. This behavior is a violation of the maxims of relation, as mere repetitions are not the relevant responses, and quantity, because repeating words lacks the amount of information required by the investigator's words.

however; some few examples present Carl as working in accordance with Grice's maxims:

*INV: up and.

*CHI: down.

*INV: there are the people.

*CHI: ah. 
*INV: they're off to school.

*CHI: on a school bus.

*INV: going to school

*CHI: on a school bus.

*INV: what did you say?

${ }^{*} \mathrm{CHI}$ : a pig.

*INV: do you wanna sing another song?

*CHI: no.

*INV: we're going to the gym.

*CHI: gym.

*INV: what color is the truck?

*CHI: green.

*INV: okay.

*CHI: (o)kay

The above extracts prove Carl's willingness to cooperate in conversation via giving the required amount of relative information. This is considered to be an observance of Grice's maxims of quantity and relation. He seems to utter brief and clear responses, following the maxim of manner His repetition of words is a form of an affirmative response to the idea presented. He is not clever a using "yes/no" as ought to be. This may go back to the child's sense that repetition is easier than uttering a new word such as "yes/no". The above extracts present that new pragmatic function of repetition. When the child repeats a word to contextually implicate "yes", this a violation of the relation maxim deriving the pragmatic implicature that a "yes" is the intended answer. The previous session contains examples of repeated words which revolve one cohesive topic usually about toys. This time again, repetition is a violation of the relation and the quantity maxims, implicating the pragmatic function of affirmative "yes":

*INV: is this your bucket?

*CHI: my bucket

*INV: is that the boy?

*CHI: the boy.

*INV: we're going to the gym.

*CHI: gym.

Carl does not use "yes/no" in his responses, that is why the investigator presents choices when Carl does not cooperate:

*INV: you want another puzzle?

*INV: or a book?

*CHI: book. 
Carl observes the Cooperative Principle by being informative as required, orderly, clear and relevant. This means that offering options helps an autistic child to cooperate in conversation according to Grice's conversational maxims.

\subsubsection{Carl: $3^{\text {rd }}$ transcription.}

In this session, which lasts about twenty-eight minutes and thirty seconds, Carl and the investigator are playing with the puzzles. The child sticks to using words that belong to the puzzle he is playing with, thus achieving cohesion in his utterance: "boat, airplane, car, duck, fish, school bus, boy, girl and big bird". He also uses the pronoun "it", the determiner "a" and the demonstrative "that" few times. The synonymy in down/bottom and the antonymy in boy/girl and up/down show Carl's developing case. It seems that Carl depends on using words that belong to the same semantic field and tend to cooccur together as a major cohesive device.

Repetition, again, is employed by Carl to serve the pragmatic function of acceptance/affirmation of the investigator's words. In this concern, Carl continues to violate the maxims of relation and quantity to implicate his agreement with the investigator:

*INV: is it up?

*CHI: up.

*INV: up here?

*CHI: up here yyy.

*INV: that's a little girl

*CHI: little girl.

*INV: it's so high up here

*CHI: high up here.

*INV: here's all the pieces

${ }^{*} \mathrm{CHI}$ : pieces.

*INV: that's at the bottom

*CHI: bottom.

In the following examples, Carl observes Grice's maxims of cooperation as he responds clearly enough with the required amount of information. This is in indication of Carl's developing conversational behavior as he begins to follow the Cooperative Principle even though the investigator does not offer options:

*INV: what is that?

*CHI: that's a boat.

*INV: what color is that?

*CHI: blue car.

*INV: I see something else.

*CHI: a school bus. 
*INV: thank you.

*CHI: thank you.

\subsubsection{Carl: $4^{\text {th }}$ transcription.}

This is the longest session as it continues for more than an hour and a half. The investigator turns focus into the bathroom. Carl's behavioral linguistic cohesive patterns vary. He uses words belonging to the topic of activity as: "turn on light, potty boy, baby potty, chi's sink, soap, bubbles, dirty and take a bath". When activities are changed to focus on playing with potato heads, Carl utters words as "ears broken, baby, chi baby, tomato baby, tomato head, pipe, mouth, big shoes, handbag, face and eyes". Moreover, Carl seems to understand pronouns as you/I and accordingly uses pronoun references as "you, it, I, he, them and his". He also utters determiners "a, an and the". His use of "let' $s$ " is a clear evidence of his desire to cooperate in a collective activity with the investigator.

Carl employs repetition to render the pragmatic meaning of "yes" or an acceptance of the investigator's acts. Again, this is a violation of the maxims of relation and quantity:

*INV: bye everybody.

*CHI: bye everybody.

*INV: I know you like faster.

*CHI: I like faster.

*INV: you need some soap?

*CHI: soap.

Carl violates Grice's maxims in the coming examples. He flouts the relation maxim to implicate "ok" when he says "bye". He, again, flouts the relation maxim to implicate "No" when he says "it's dark" and "it's not Chi's potty". He flouts the quantity maxim by echoing the investigator's words and, thus, being more informative than required in "I go to a $[=$ ? the] big boy potty"

*INV: let's go this way Chi.

*CHI: bye.

*INV: let's go to the potty.

*CHI: it's dark.

*INV: what do we needta do?

*CHI: I need turn on light?

*INV: you go in the big potty now.

*CHI: I go to a [=? the] big boy potty.

*INV: now you go on the big boy potty.

*CHI: it's not Chi's potty. 
Assuming that Carl cooperates with the investigator, the child flouts the maxim of relation in the following examples to implicate that the head needs a pipe. This flout may not be deliberate due to Carl's incompetence as to language:

*INV: what does this potato head need?

*CHI: I found a pipe.

Carl, again, flouts the maxim of relation to implicate that he cannot open the back of the baby toy to search for the pipe:

*INV: open it.

*CHI: I need help.

Other examples of pragmatic cooperation on the part of the child are the coming instances in which the child answers according to the Cooperative Principle by uttering the required amount of information, being relevant and brief. It is noticed that the child begins to use a direct "yes" instead of repeating the investigator's words to implicate "yes". This is a developing skill in conversational cooperation on the part of the child. In saying "I found a $[=$ ? the $]$ pipe" and repeating it instead of answering the investigator's question, the child flouts the maxims of relation and quantity to deliver the implied meaning "yes":

*INV: is it in the box?

*CHI: yes.

*INV: did you find it?

*CHI: I found a [=? the] pipe right here.

*INV: is that where the eyes go?

*CHI: yes [=! laughs]

*INV: you hid it in the little boy.

$* \mathrm{CHI}$ : I found a [=? the] pipe.

*CHI: let's open this

The above sentence "let's" marks Carl's willingness to initiate a cooperative action. The following examples show Carl's cooperation in conversation by uttering the right amount of required information:

*INV: is that Spot?

*CHI: yes.

*INV: who's in there?

*CHI: bear.

In the coming examples, Carl flouts the maxims of quantity and relation by adding extra irrelevant information implicating that happiness is spread to all around him:

*INV: the turtle says hi Spot.

*CHI: it's a [=? the] happy turtle.

*INV: what else is in here? 
*CHI: Spot is happy.

*CHI: a [=? the] momma is happy.

Carl accepts to cooperate in conversation with the investigator via being informative enough, relevant and clear. Thus, he observes the conversational maxims. This time he uses "uh" as a sign of acceptance:

*INV: can you hear me?

*CHI: \&-uh huh.

It is obvious that Carl develops cohesive/pragmatic skills as the sessions continue. On comparing Carl's linguistic contribution across the four sessions, it is evident that after the first session Carl gets more involved in conversation, shows more conversational cooperation and uses words belonging to the presented topic as devices connecting ideas. He uses articles, references and understands pronouns. Though he does not answer many questions and remains silent in most situational utterances, he shows that linguistic practice is helpful in making autistic children cooperate in conversation.

\subsection{Target Child: Josh}

\subsubsection{Josh: $1^{\text {st }}$ transcription.}

In this session, which lasts about an hour and fifteen minutes, we have three participants: the autistic child Josh, the investigator and the Camera man operator. Apart from "yyy" which is described as being a jargon, Josh does not cooperate verbally with any meaningful word. He does not talk to neither the investigator nor the camera man operator. This is a delayed case of autism than that of Carl as Carl shows more cooperation in his first transcription.

\subsubsection{Josh: $2^{\text {nd }}$ transcription.}

In this short session which lasts about nine minutes, Josh employs only words that belong to the field of puzzles as the only cohesive device detected. Words as "puzzle, chick, giraffe and pig" refer to Josh's cohesive discourse. No other cohesive devices are noticed.

In this session, Josh starts to cooperate verbally with the investigator. He employs repetition to implicate his acceptance of the investigator's words. In doing so, he violates the maxims of relation, as he does not utter the relevant response. He also does not give the required information, thus flouting the quantity maxim. This is similar to Carl's verbal communication:

*INV: should we do the puzzle?

*CHI: puzzle.

*INV: you took the giraffe out.

${ }^{*} \mathrm{CHI}$ : giraffe

*INV: you have the pigs.

*CHI: pig 
*INV: it's wet.

*CHI: wet.

\subsubsection{Josh: $3^{\text {rd }}$ transcription.}

Repetition is, again, an implication of the child's acceptance, the same practice which is adopted by Carl:

*INV: more dots.

*CHI: dots.

*INV: dots

*CHI: dots.

*INV: and dots

*CHI: dots.

*INV: boys and girls.

*CHI: boys yyy.

*INV: let's go find the doors.

*CHI: doors.

Josh cooperates according to Grice's maxims by giving the required amount of relative information in:

*INV: are we going to go up or down?

*CHI: up.

*INV: what are these?

*CHI: dots.

*INV: what do we needta do?

*CHI: push the door.

Though this session is about 44 minutes, the child's verbal cooperative acts are few with limited examples of cohesive devices: the use of "I", "the", the ellipsis in "I want more" and the words related to walking activity as "doors, boys". It seems that Josh is somehow delayed in his linguistic development than Carl. This transcription, however, shows Josh's developing skill of cooperative interacting and use of more cohesive devices.

\subsubsection{Josh: $4^{\text {th }}$ transcription.}

This is the final session concerning Josh. It lasts about forty-eight minutes and thirty-seven seconds. It is expected that more cooperative and cohesive acts are to be remarked.

Josh repeats the investigator's words to implicate an acceptance:

*INV: inside?

*CHI: inside.

*INV: inside?

*CHI: inside. 
Josh flouts the relation maxim when he expresses his wants instead of answering the investigator's question. This is a sign of autistic children's selfconfinement:

*INV: what do we do?

${ }^{*} \mathrm{CHI}$ : I want you to open the door.

*INV: what do we do here?

*CHI: I want you to open the door.

Josh's linguistic behavior is fewer than Carl even at this final session. Josh's use of words, in spite of their being so few, as "door, inside, pull", of articles as "the, a" and of pronouns as "I, you" mark the only cohesive devices employed. Although Josh advances his cooperative verbal interaction and his cohesive devices as the sessions proceed, his advancement is still overdue in comparison with Carl.

\subsection{Target Child: Marshall (Mars)}

\subsubsection{Mars: $1^{\text {st }}$ transcription.}

Just like Carl and Josh, Mars employs repetitions to implicate his acceptance:

*INV: let's go up the stairs.

*CHI: up.

Though Mars follows Grice's cooperative maxims when he obeys the investigator at first, Mars utters words that seem irrelevant to the questions but implicate "yes". Contrary to Carl and Josh who use repetitions, Mars uses words related to the topic of speech to implicate "yes":

*INV: say bye bye people.

*CHI: bye bye.

*INV: can you hear them?

*CHI: chickens.

*INV: can you push the door open?

*CHI: bye.

Mars cannot answer the questions about his ability as "can you hear" and "can you push". It seems that "yes" is a linguistic burden shared by autistic children who implicate "yes" by employing repetition or using words related to the topic of conversation.

\subsubsection{Mars: $2^{\text {nd }}$ transcription.}

Mars repeats the investigator's words to implicate acceptance/affirmation of them, which is a violation of the relation and quantity maxims:

*INV: five trucks.

*CHI: five trucks.

*INV: one cake.

*CHI: one. 
He cooperates with the investigator in the few examples of repeating the numbers with him, a thing referring to his lacking in skills that help him cooperate according to the maxims and say "yes". Though this session is about one hour, it presents few cooperative examples on the part of Mars. Accordingly, cohesive devices are also few including only words related to playing as "truck, cake" and the ellipsis of cake in "one, two".

\subsubsection{Mars: $3^{\text {rd }}$ transcription.}

Mars continues to employ repetition, violating the relation maim, to implicate acceptance:

*INV: here's a five.

*CHI: five.

*INV: six.

*CHI: six

*INV: seven.

*CHI: seven.

*INV: four.

*CHI: four.

*INV: five.

*CHI: five.

Another example of Mars's observance of Grice's maxims is:

*INV: what are these?

*CHI: dolls.

Though this session lasts about an hour, Mars's contribution is only the uses of numbers and words related to his playing as "bikes, balls, bears and dolls". No more examples of cooperation or cohesion are noticed.

\subsubsection{Mars: $4^{\text {th }}$ transcription.}

Mars implicates "yes" through repetition, which is a flout of both maxims of relation and quantity:

*INV: here's the car.

*CHI: car.

*INV: is that a green car?

*CHI: a car.

*INV: you put the man on the horse.

*CHI: man.

*INV: is that a seal?

*CHI: seal.

*INV: fruits.

${ }^{*} \mathrm{CHI}$ : fruit. 
Mars, playing puzzles with the investigator, cooperates verbally by following Grice's maxims in:

*INV: what's that?

*CHI: a bike.

*INV: put it in

${ }^{*} \mathrm{CHI}$ : right there.

*INV: stop.

*CHI: go go go.

*INV: what's that?

${ }^{*} \mathrm{CHI}:$ a plane.

*INV: what's that?

*CHI: tractor.

This is a sign of developing skills.

Cohesive devices include words belonging to the same topic of playing as: "car, truck, bike, man, fruits, honey, plane, tractor, duck, elevator, elephant, bird, cheep, doggie, bunny and elephant", antonymy in "men, women". This session lasts about two hours. It shows more cooperative endeavors on the part of Mars.

\subsubsection{Mars: $5^{\text {th }}$ transcription.}

Generally, the same linguistic features appear. The child repeats, violating the relation and the quantity maxims, words to implicate his acceptance as in:

*INV: drive the tractor.

$* \mathrm{CHI}$ : red tractor.

*INV: pig

*CHI: hi pig.

*INV: a frog?

*CHI: a frog.

*INV: chapter two.

*CHI: chapter two.

*INV: a a bulldozer

*CHI: a bulldozer.

*INV: she's getting tomatoes

*CHI: tomato.

He violates the relation maxim because his responses should have been an acceptance or a denial of the investigator's commands and questions. He also flouts the quantity maxim by being less informative as is required to implicate his understanding of the investigator's words and his inability to answer according to the Cooperative Principle:

*INV: look here.

*CHI: toy box. 
*INV: Chi, do you want your bucket or the toy box?

*CHI: Winnie Pooh.

*INV: look we need a brown...+

*CHI: brown key.

*INV: orange?

*CHI: orange door.

He invites the investigator to cooperate as in:

*CHI: look there's a bird.

*CHI: tweet tweet

*CHI: look at that woman.

This session lasts about two hours. It shows Mars's developing cooperation through the same strategies of repetition and responding with relative words instead of "yes". He seems to share the same feature of using the technique of repetition to implicate his acceptance. "Yes" and "No" seem to be a difficult option in autistic cases. Mars's cohesive devices are mostly the words belonging to the same field as 'tractor, toy box, Winnie Pooh (a toy), pig, bee, bird, frog, truck, race car, dinosaur, train". His choice of other cohesive devices is so limited, with few examples of 'a' and "that".

\subsection{Target Child: Roger}

\subsubsection{Roger: $1^{\text {st }}$ transcription.}

Roger repeats the investigator's words to implicate his acceptance, just like the previous three boys. He should have uttered words which (dis)agree with the investigator's. Instead, he contributes via repeating the investigator's words or using related ones. So, he is irrelevant to the topic and less informative than is required. This is a violation of the relation and quantity maxims.:

*INV: here's the blocks.

*CHI: block.

*INV: get set.

*CHI: go.

${ }^{*} \mathrm{CHI}: \quad$ get set

*CHI: go.

Though this session lasts about an hour and forty-nine minutes, Roger's contribution is nearly limited to few examples in which he repeats words related to the activity of playing. This may be due to the fact that this is the first session. Similar to the previous three boys, Roger's sole cohesive device is the use of playing-related words. He also has a difficulty in saying "yes" or "No", like the other three boys.

\subsubsection{Roger: $2^{\text {nd }}$ transcription.}


In this session that lasts for twenty-one minutes, the investigator is, as usual, playing with Roger who repeats words to serve the function of implicating acceptance, this time, of the idea of playing itself as it is noticed that Roger repeats words related to the previous session. He flouts both the relation and quantity maxims:

*INV: open his mouth.

*CHI: on yyy mark.

$* \mathrm{CHI}$ : get set.

*CHI: go.

*INV: there's a square cookie.

*CHI: get set.

The child's linguistic contribution is still so few with no obvious examples of cohesion to examine.

\subsubsection{Roger: $3^{\text {rd }}$ transcription.}

*INV: open the door.

$* \mathrm{CHI}: \quad \mathrm{a}[=$ ? the $]$ door.

This is an hour session. Apart from the above example that shows Roger's violation of the maxims of relation and quantity via his repetitive utterance, Roger nearly refrains from any meaningful verbal cooperation.

\subsubsection{Roger: $4^{\text {th }}$ transcription.}

Repetition is not numerous. This is nearly the only example serving the same function of implicating acceptance:

*INV: hat.

*CHI: a hat.

Roger rarely speaks even in this advanced session. He cooperates via few words as "hat", "shirt", "hands" and "cow", which cohere with the activities of playing. This session lasts for an hour. In spite of that, Roger does not show verbal development as the other boys. Roger is not as cooperative as the previous kids.

\subsection{Target Child: Sid}

\subsubsection{Sid: $1^{\text {st }}$ transcription.}

For about two- hour session, Sid hardly utters a meaningful word.

\subsubsection{Sid: $2^{\text {nd }}$ transcription.}

In this two-hour session, Sid rarely utters a word.

\subsubsection{Sid: $3^{\text {rd }}$ transcription.}

*INV: it's Tony.

*CHI: hi.

In this session that lasts about an hour and twenty-five minutes, the above example is nearly the only meaningful verbal contribution detected. Sid violates 
Grice's relation and quantity maxims to implicate that he understands the investigator's words but is unable to say "yes".

\subsubsection{Sid: $4^{\text {th }}$ transcription.}

Examples of Sid's violation of the relation and quantity maxims through mere repetitions implicating his acceptance:

*INV: and a puppy.

*CHI: puppy.

$* \mathrm{INV}$ : is it the boy?

*CHI: boy.

*INV: is it an owie?

*CHI: owie.

*INV: ponies?

*CHI: ponies.

*INV: is it a boy and a bike?

*CHI: bike.

*INV: $\quad \&=$ gasp there's the bears again.

*CHI: bear.

*INV: bikes?

*CHI: bikes.

*INV: are they eating gold fish?

*CHI: goldfish.

*INV: they hafta move.

*CHI: move.

*INV: it's empty.

*CHI: empty.

*INV: do you see the birds flying?

$*$ CHI: flying.

*INV: can you tell her hi?

*CHI: hi.

*INV: can you say hi?

*CHI: hi.

Examples of Sid's cooperative verbal interaction via responding in accordance with the Cooperative Principle are:

*INV: what's that?

*CHI: a [=? the] butterfly.

*INV: the little red caboose always came

*CHI: last.

*INV: gasp what are those?

$* \mathrm{CHI}$ : bear. 
*INV: gasp what's that?

CHI: bus.

*INV: what do you see?

*CHI: bus and bus.

*INV: what else do you see?

*CHI: airplane.

*INV: say good night.

*CHI: good night.

*INV: would you like to come in and eat supper?

*CHI: yes.

*INV: are they going to school?

*CHI: yes.

*INV: what's in there?

*CHI: computer.

*INV: what's this?

*CHI: elevator.

*INV: which way?

${ }^{*} \mathrm{CHI}$ : that way.

*INV: do you see the motorcycle?

*CHI: yes.

*INV: are you ready for snack time?

*CHI: yes

Sid cooperates well in this session. His cohesive devices are the words that echo the investigator's or reply to them.

\section{Conclusion}

This research is about verbal communication by autistic children. It discusses autistic discourse from two angles: that of the level of observing or violating the Cooperative Principle/maxims in the autistic verbal interaction and that of using cohesive devices. Echolalia is, as suggested by its name, the echoing of words. It is a symptom of all children with autism to repeat, or to echo, words uttered by others. This research considers echolalia as a positive sign of interactional 
contribution. Children show individual differences in their developing practices of echolalia. Carl, for instance, shows more developmental interaction than Roger. In spite of that, all children repeat words uttered by the investigator in order to implicate their acceptance of the activity expressed. This is a violation of the relation maxims, because mere repetition is not the required answer. It is also a violation of the quantity maxim because the boys do not give the required information when they employ repetition. Their violation is due to their inability to express themselves and respond in accordance with the maxims of cooperation, especially when it comes to express an acceptance or a denial of the investigator's words. However, their repetitive discourse is a positive sign in itself because they may remain silent without saying a word. All instances of the children's verbal behavior are almost included in the analysis section. Apart from these instances, the children do not show any meaningful verbal communication throughout the session period.

Examples of cooperative acts done by autistic children tell that these children employ repetition of linguistic items as a sign of their desire to communicate. The boys are not cooperative enough as to responding with yes/no to the investigator's words, they repeat the accepted or the desired word(s) and sometimes use words related to the topic. It seems that repetition is retrieved with a less effort than uttering an affirmative "yes". All children violate the relation and the quantity maxims via the same strategy: that of echolalia.

As far as cohesive devices are concerned, all children stick to the topic initiated by the investigator, which is always about puzzles or ordinary daily activities. In doing so, they utter words that are connected to this topic-a thing which is considered to be a sign of cohesion. Few examples of the use of articles and pronouns are detected. Generally, all cohesive devices, except for using words that revolve around the same topic, are absent in autistic communication.

This study suggests that repetition may be considered as a positive sign and that the autistic child desires to cooperate in conversation, but is incapable of conforming to the Cooperative Principle. Accordingly, this very repetition should be rewarded, verbally, and be taken as a step to move forward and train the child to repeat and utter a comment or express his desire simply by saying yes/no before repeating. This will train the child to respond in accordance to the maxims of cooperation. This study also suggests that the investigator should make use of various cohesive devices, especially synonymy and antonymy, that are somehow related to echolalia and are easily understood. These devices may be easier to be applied by autistic children. Uttering similar or opposite items helps the child to practice more words and develop skills of language. 


\section{References}

American Psychiatric Association. Diagnostic and statistical manual of mental disorders: DSM-V. Washington, D.C.: American Psychiatric Association; 2013.

Cabley, P. (2001). The routledge companion to semiotics and linguistics. London \& New York: Routledge

Downes, W. (1998). Language and society. Second edition. Cambridge: Cambridge University Press.

Grice, H.P. (1975). Logic and conversation, in P. Cole \& J.L. Morgan (Eds.), Syntax and semantics. New York: Academic Press.

Hagan, K.D.P. (2017). Discourses in autism assessment and diagnosis. Available at https://oro.open.ac.uk/55623/1/Redacted\%20Hagan\%20PhD\%20Thesis\%20A utism\%20Discourses\%202017.pdf

Halliday, M. \& Hasan, R. (1976). Cohesion in English. London: Longman.

Halliday, M. A. K. \& Matthiessen, C. M. I. M. (2004). An introduction to functional grammar (3rd ed.). London: Arnold.

Halliday, M. A. K. (1985). An introduction to functional grammar. London: Arnold.

Harmer, J. (2004). How to teach writing. Pearson Educated Limited.

Hasan, R. (1984). Coherence and cohesive harmony. In J. Flood (Ed.), Understanding reading comprehension: Cognition, language and the structure of prose (pp. 181-219). Newark, DE: International Reading Association.

Helland, W.E. \& Helland, T. (2017). Emotional and behavioural needs in children with specific language impairment and in children with autism spectrum disorder: The importance of pragmatic language impairment. Available at https://www.sciencedirect.com

Hoey, M. (1991). Patterns of lexis in text. Oxford: Oxford University Press.

Hofmann, Th. R. (1993). Realms of meaning. An introduction to semantics. London \& New York: Longman

Loukusa, S., Makinen, L., Gauffin, S., Ebeling, H., and Leinonen, E. (2018). Assessing social-pragmatic inferencing skills in children with autism spectrum disorder. Available

at

https://www.sciencedirect.com/science/article/pii/S0021992417300229

Lyons, J. (1996). Linguistic semantics. An introduction. Cambridge: Cambridge University Press.

Lyons. J. (1983). Language meaning and context. London: Fontana. 
Maciejewska, E. (2019). Discourse analysis as a tool for uncovering strengths in communicative practices of autistic individuals. Available at https://journals.sagepub.com/doi/full/10.1177/1461445619829237

Martin, J. R. (1992). English text. System and structure. Amsterdam: Benjamins McCarthy, M. (2001). Issues in applied linguistics. Cambridge University Press. Rollins P. R. (1999). Pragmatic accomplishments and vocabulary development in pre-school children with autism. American Journal of Speech-Language Pathology: A Journal of Clinical Practice, 8, 85-94.

Rollins, P. R., \& Snow, C. E. (1998). Shared attention and grammatical development in typical children and children with autism. Journal of Child Language, 25(3), 653-673.

Rollins, P. R., Wambacq, I., Dowell, D., Mathews, L., \& Reese, P. B. (1998). An intervention technique for children with autistic spectrum disorder: Joint attentional routines. Journal of Communication Disorders, 31(2), 181-193.

Tager- Flusberg, H., Paul, R, \& Lord, C. (2005). Language and Communication in Autism. In Fred R. Volkmar Rhea Paul Ami Klin \& Donald Cohen ( Ed.), Handbook of autism and pervasive developmental disorders, Volume 1, Third Edition. John Wiley\& Sons, Inc.

Tager-Flusberg, H. \&Anderson, N. (1991). The development of contingent discourse ability in autistic children. Available at https://onlinelibrary.wiley.com/doi/abs/10.1111/j.1469-7610.1991.tb00353.x 